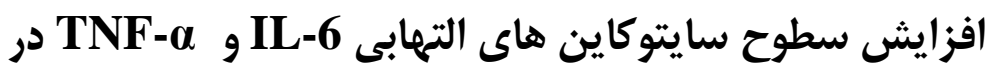

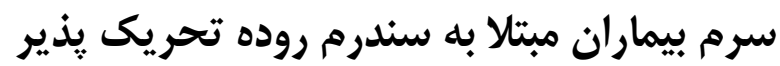

$$
\text { مرضيه عزيزيان?، حبيب اله تركى'، اسد ميرزايى }
$$

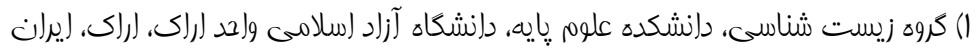

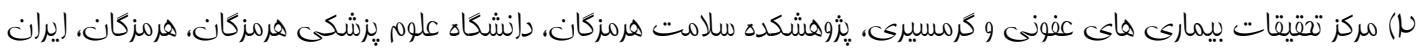

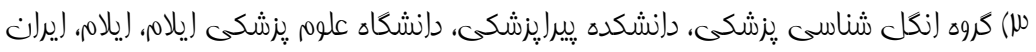

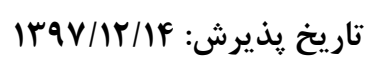

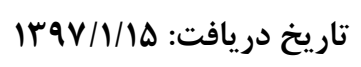

\section{קكيده}

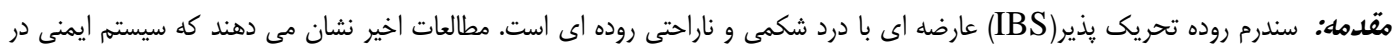

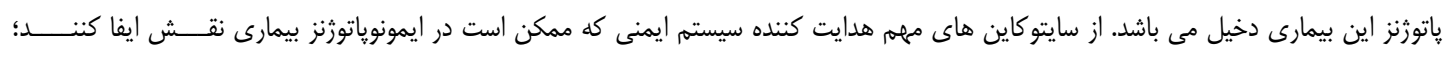

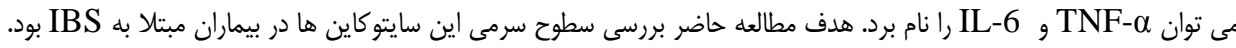

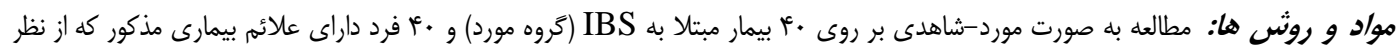

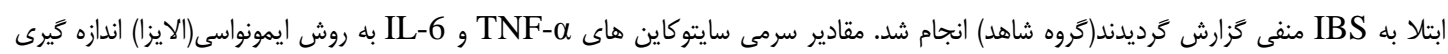

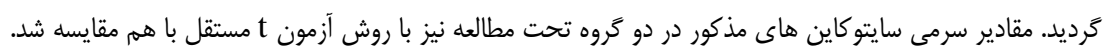

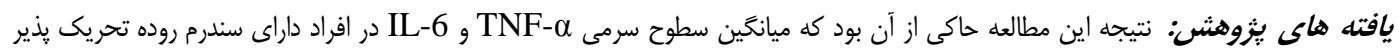

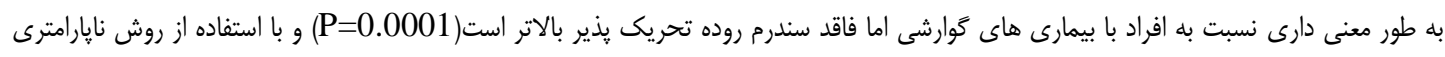

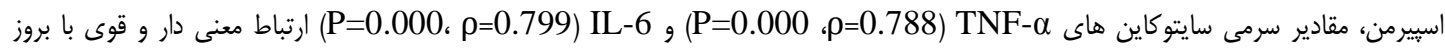
تشان دادند.

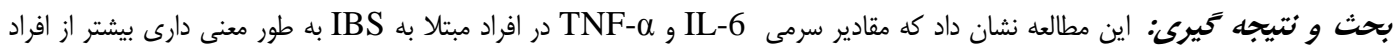

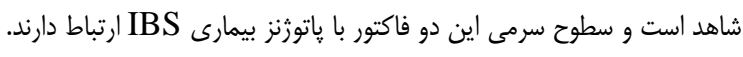

وازهه هاى كليدى: سندروم روده تحريك يذير، ايتتر لوكين - فواكتور نكروز دهنده تومور آلفا، الايزا

Email:amirzaeii@yahoo.com

Copyright (C) 2019 Journal of Ilam University of Medical Science. This is an open-access article distributed under the terms of the Creative Commons Attribution international 4.0 International License (https://creativecommons.org/licenses/by-nc/4.0/) which permits copy and redistribute the material, in any medium or format, provided the original work is properly cited. 


\section{مواد و روش ها}

در اين مطالعه مورد-شاهدى • ع ب بيمار مبتلا به

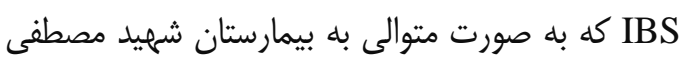

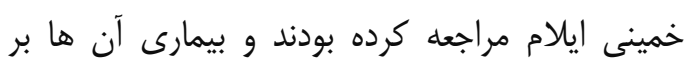

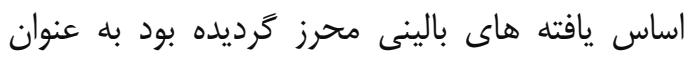

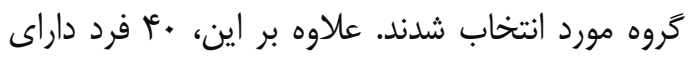

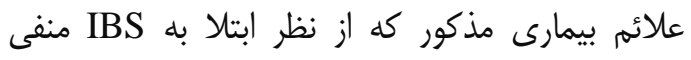

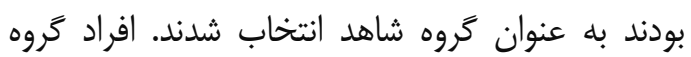

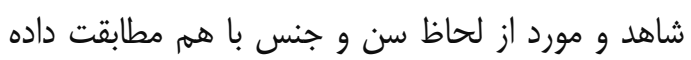

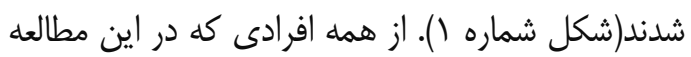

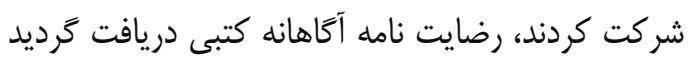
و مطالعه در كميته اخلاق دانشخاه(شماره كميته اخلاق دانشخاه EC/92/H/132) مورد تاييد قرار كرفت. افراد

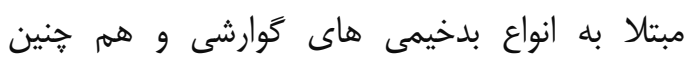

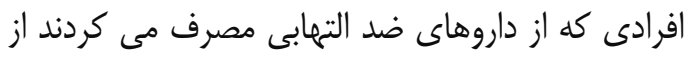

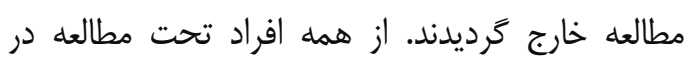

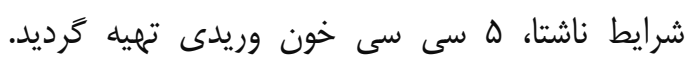

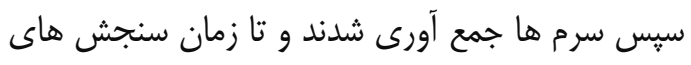

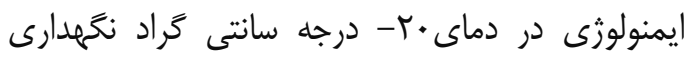

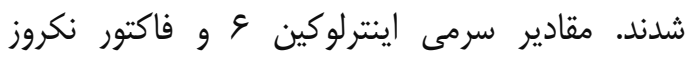

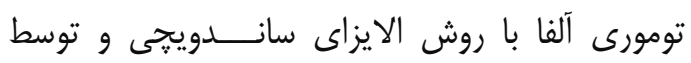
كيت هاى تجارى مربوطه(ab46027 براى اينترلوكين

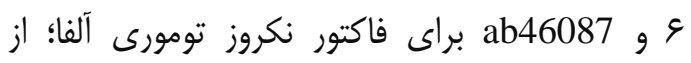

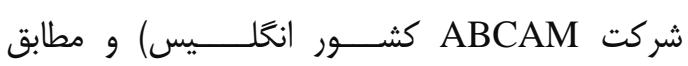
دستورالعمل كيت سنجش گَرديدند. داده هاى مطالعه

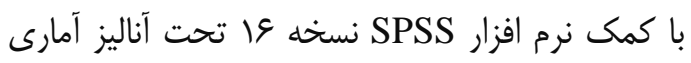
قرار گرفتند. براى مقايسه مقادير سرمى اينترلوكين

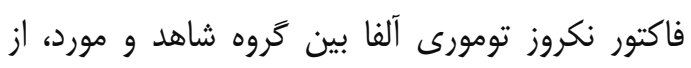

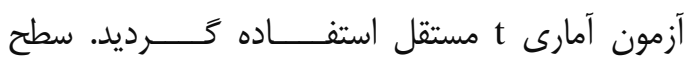
معنى دارى آمارى در اين مطالعه كمتر از

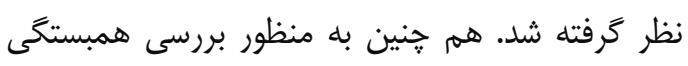
بين بروز بيمارى IBS و سطوح سرمى هر سايتوكاين از

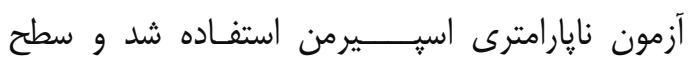

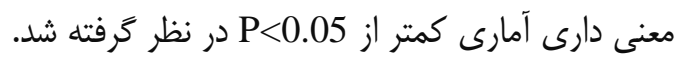

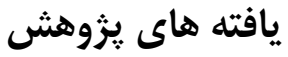

در مجموع هشتاد نمونه سرم|• أ نفر بيمار مبتلا به

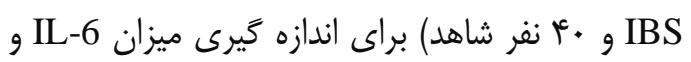
TNF- $\alpha$

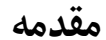

بيمارى سندرم روده تحريك يذير عارضه اى است

كه باعث تغيير در عملكرد روده شده، با درد شكمى و وردي ناراحتى روده ایى همراه است. در اين بيمارى واكنش

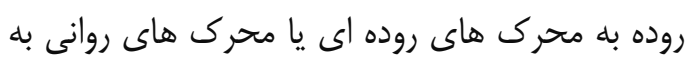

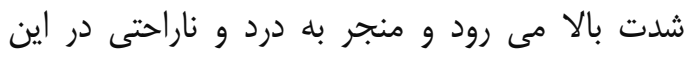

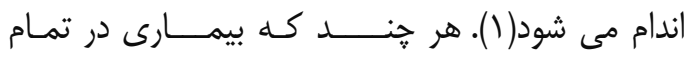
رده هـاى سنى ديده مى شود ولى روش هاى درمانى

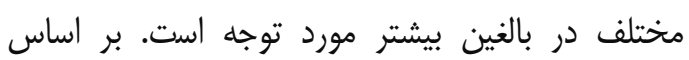

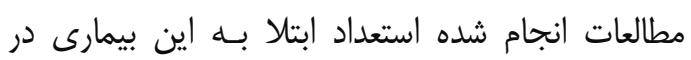

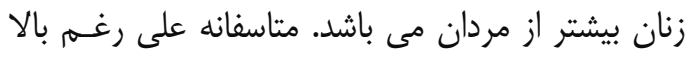

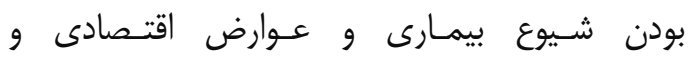

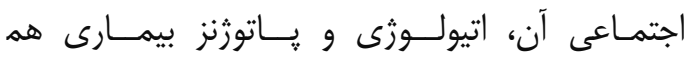

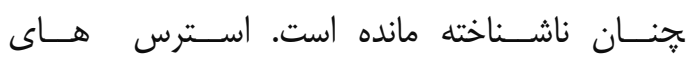

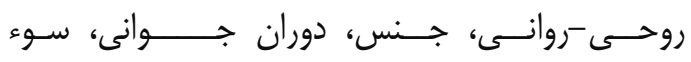

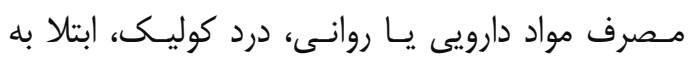

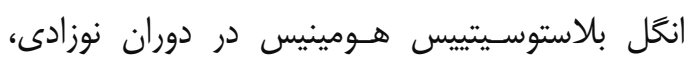

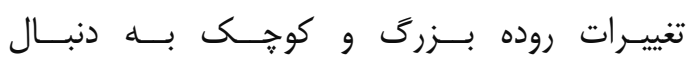

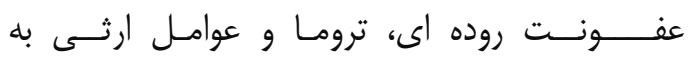

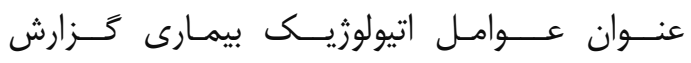
شـده انــد(ه-r). محققان نشان داده اند كه سيسته

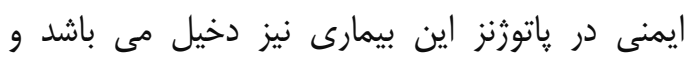

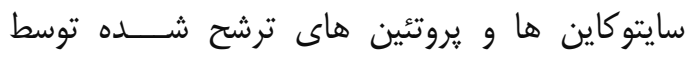

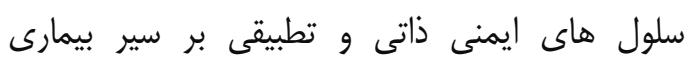

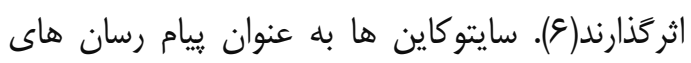

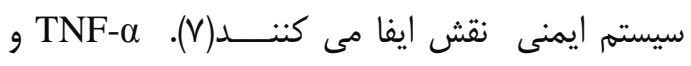
واسطه هاى اصلى پاسخ التهابى حاد مى باشد.

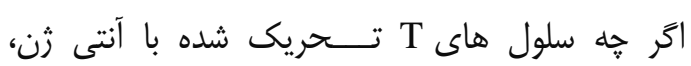
سلول هاى كشنده طبيعى و ماست سل ها مى تو توانند

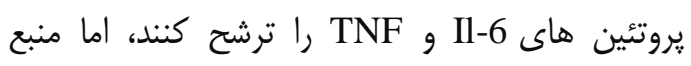
سلولى اصلى فاگوسيت كننده هاى تكى هسته ایى فعال

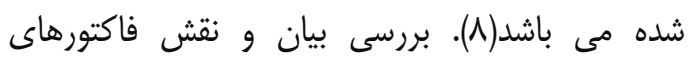

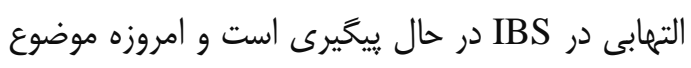
بسيارى از تحقيقات مى باشد(1) يزوهش بررسى سطوح سرمى ايتترلوكين ؤ و فاكتور

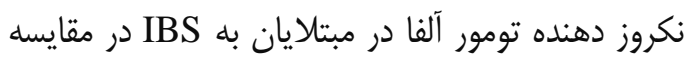

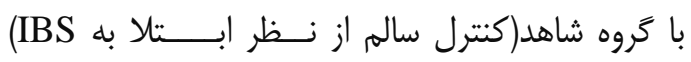
مى باشد. 
كرديد. ميزان ايتترلوكين و در گروه IBS و گروه كنترل

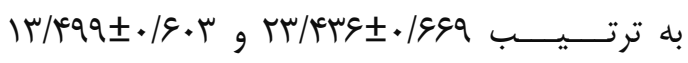
ييكوگرم در ميلى ليتر اندازه گيرى شد(شكل شماره r)

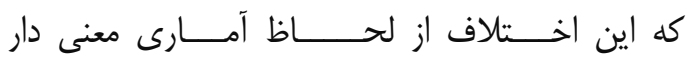

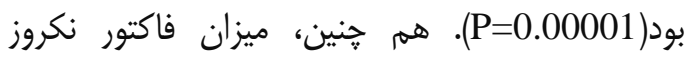

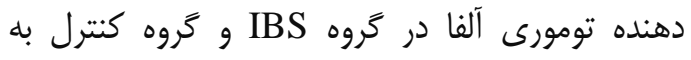

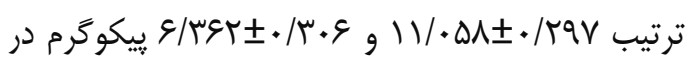

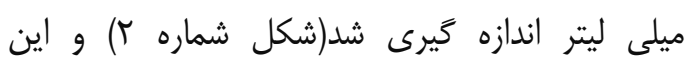

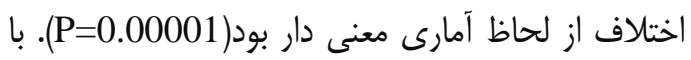
استفاده از روش همـــــستخى نازيارامترى اسبيرمن،

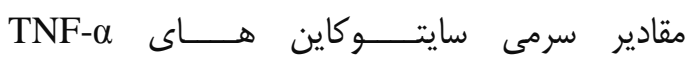

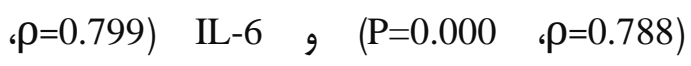
ارتباط معنى دار و قوى با بروز P=0.000 نشان
مقادير ضريب تغييرات درون سنجى و برون سنجى

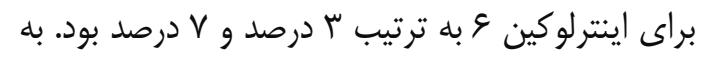
همين ترتيب، اين مقادير براى فاكتور نكروز تومورى برى بتئ

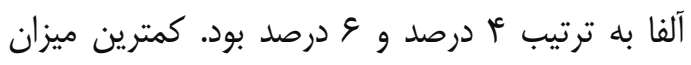

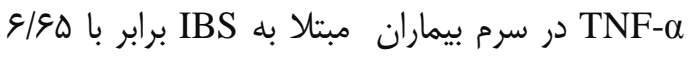

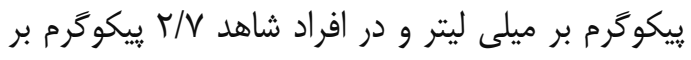

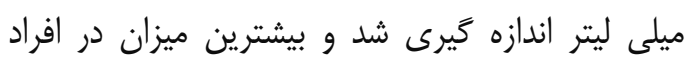

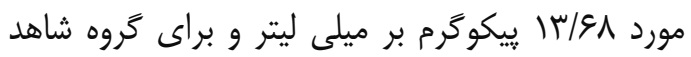

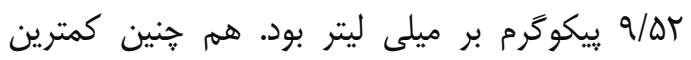

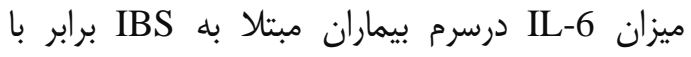

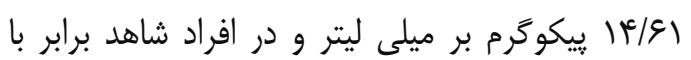

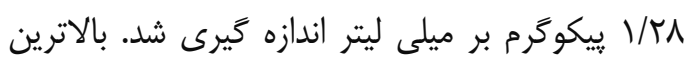

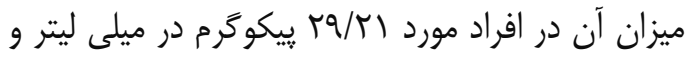

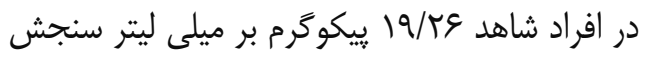

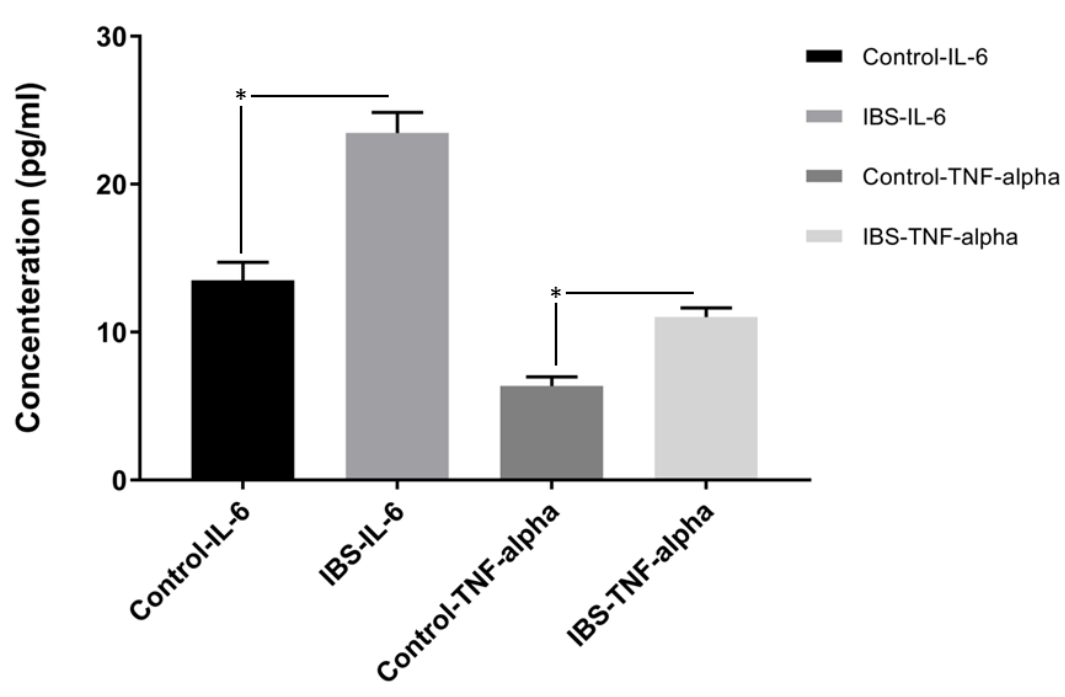

شكل شماره (. نمودار دموكر افيك جمعيت بيمار و كنترل با توجه به محدوده سنى و جنسيت 


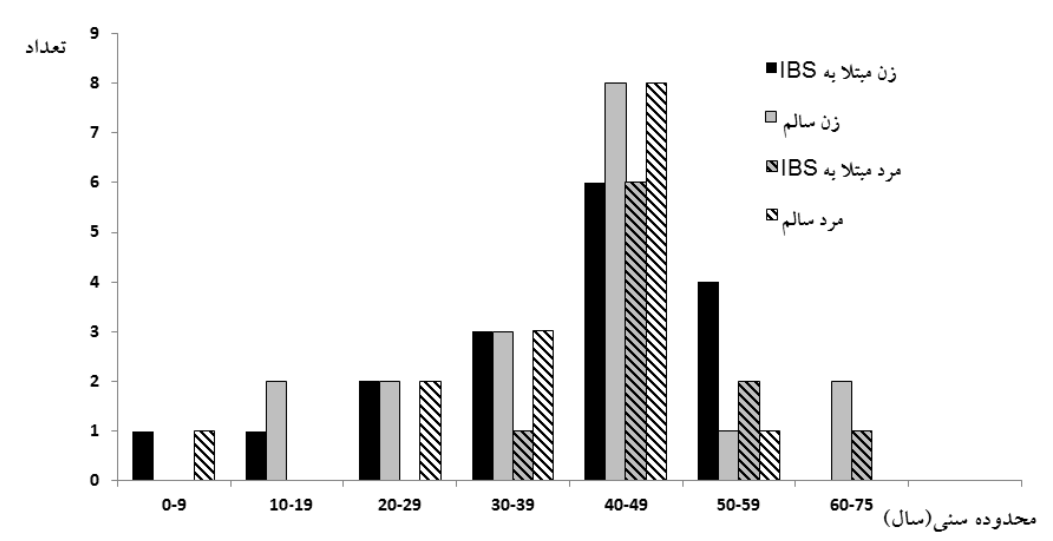

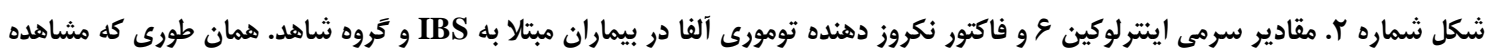

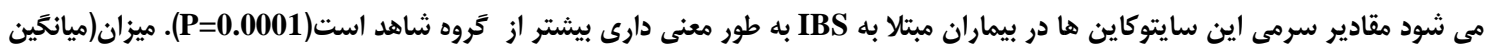

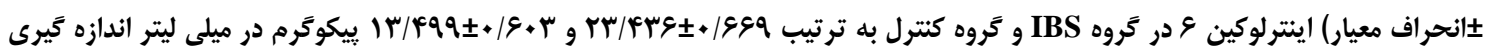

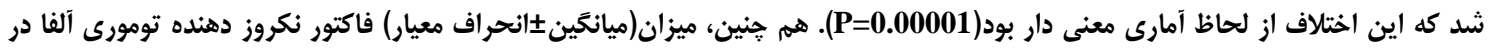

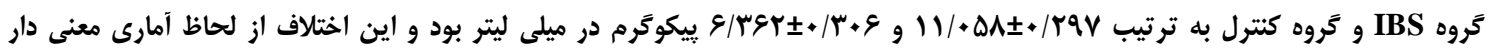

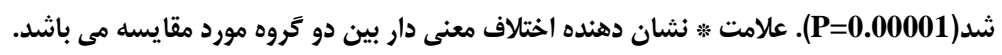

لنفوسيت ها، ماست سل ها و سلول هاى انتروكرومافين

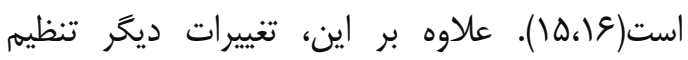

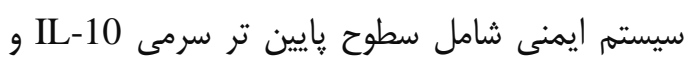

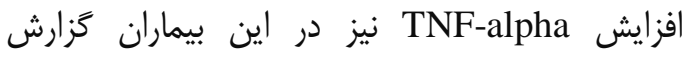

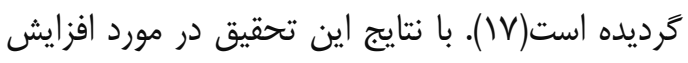
معنى دار غلظت سرمى TNF-alpha با نتايج حاصله در اين مطالعه هم خوانى دارد و هر دو تائيدكننده

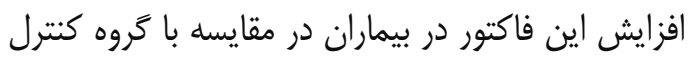

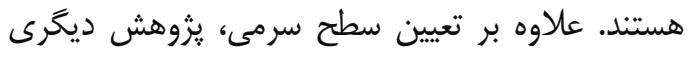

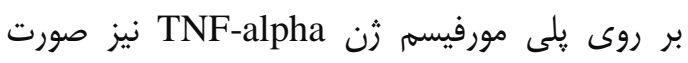

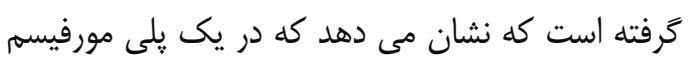

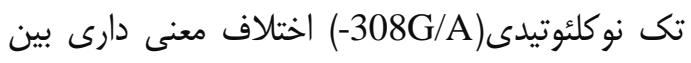

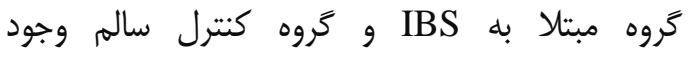

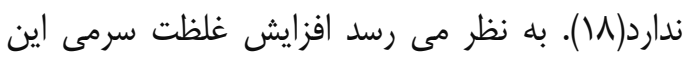
فاكتور يروتئينى وابسته به مسيرهايى غير از اختلافئ رسات

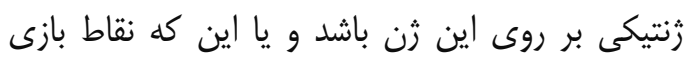

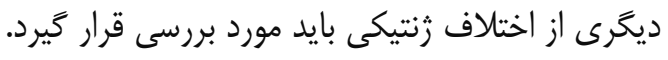

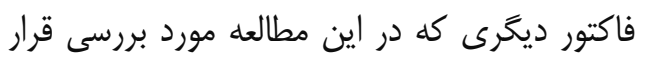

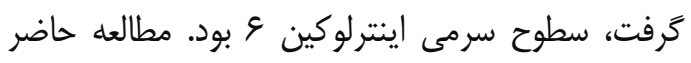
نشان داد كه سطوح سرمى IL-6 نيز در بيماران مبتلا

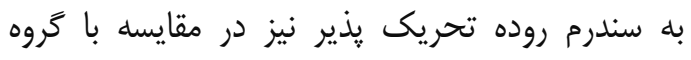
كنترل سالم بيشتر است. مطالعه اخير توسط دimothy

\section{بحث و نتيجه كَيرى}

هاتوفيزيولوزى بيمارى سندرم روده بيرى تحريك يذير

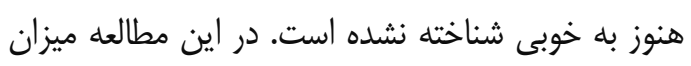

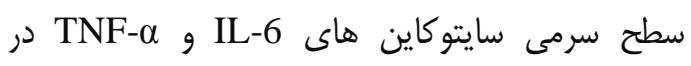

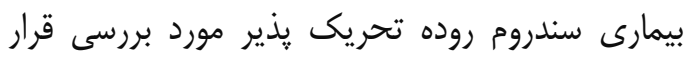

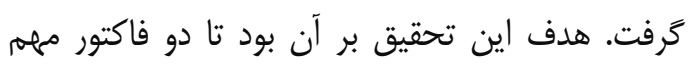

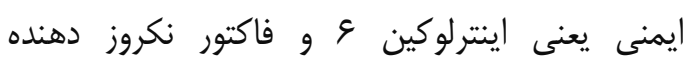

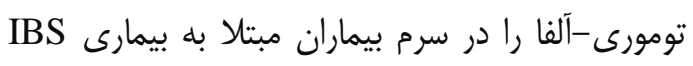

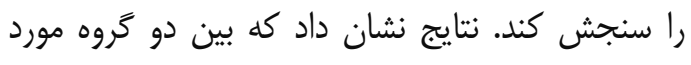

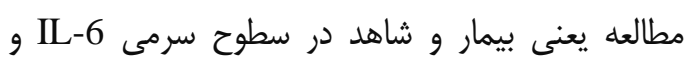
TNF- $\alpha$ با استفاده از روش نايارامترى اسبيرمن، مقادير سرمى إدى داري سايتوكاين هاى IL-6 و TNF-

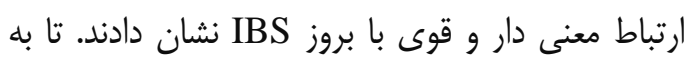

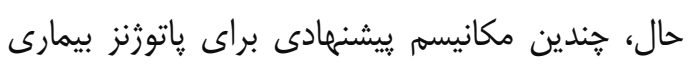

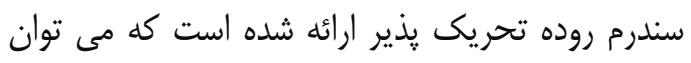
از بين آن ها به تغيير در نحوه تحرى روديك روده، بيش آنس

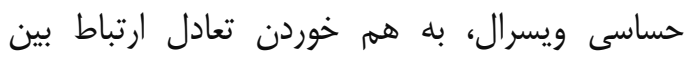

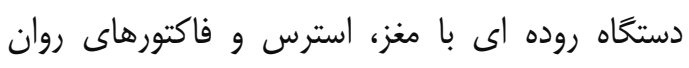

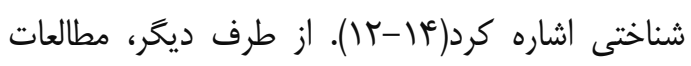

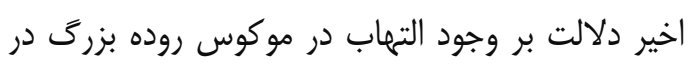

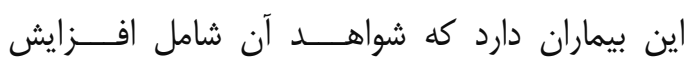


اما در حالت خودايمنى با شناسايى آنتى ثن هاى خودى بيمارى خود ايمنى اتفاق مى افتد. از جانب ديكر تمايز به Th2 منجر به ترشح سايتوكاين هايى نظير IL-4

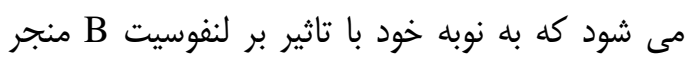

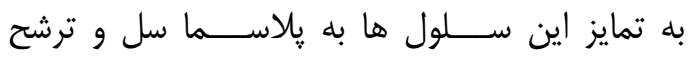

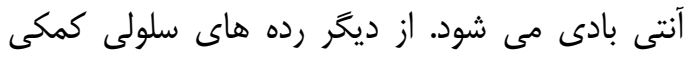

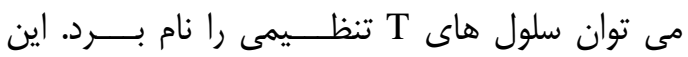

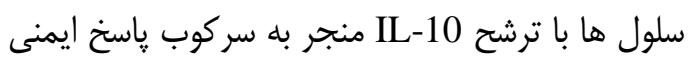
مى شوند و نقش مهارى بر سيستم ايمنى دارند و بدين كونه مانع از واكنش بيش از حلد ملد سيستم ايمنى و آسيب

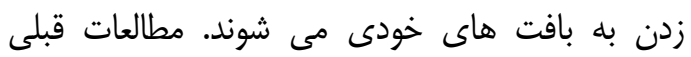
نشان مى دهد كه سلول هاى سيسته ايمنى از جمله

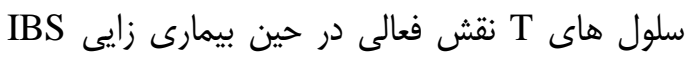

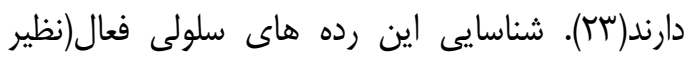

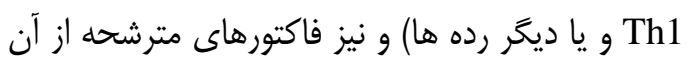

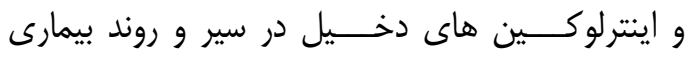

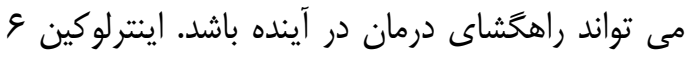
سايتوكاينى است كه در هر دو ايمنى ذاتى و تطبيقى دانى داني

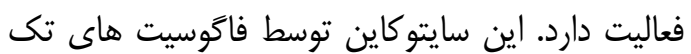

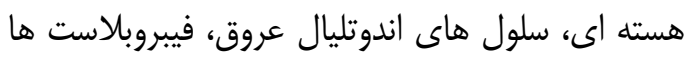

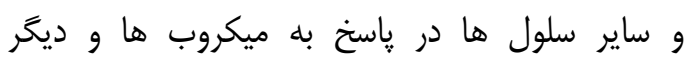

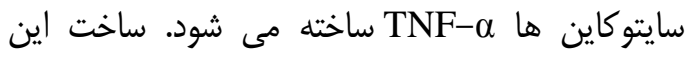

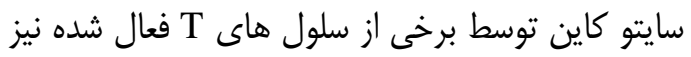

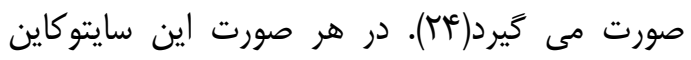
توليد شده مى تواند بر سلول T بكر اثر كرده و و تعادل

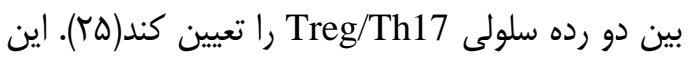

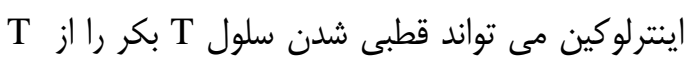

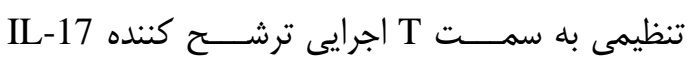

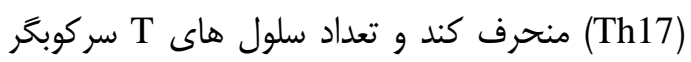

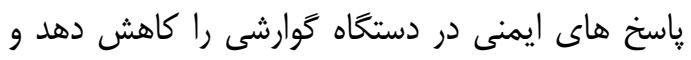

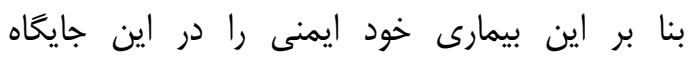

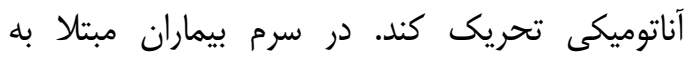

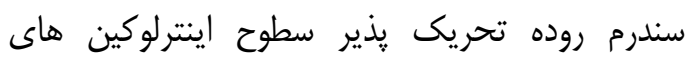
التهابى افزايش مى يابد. افزايش معنى دار درسطوح

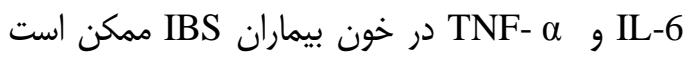
ناشى از تقويت ياسخ ايمنى سلولى در اثر افزايش توليد

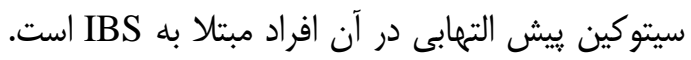
يزوهش هاى اخير نشان داده است كه فاكتور نكروز
G. Dinan

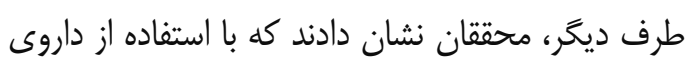

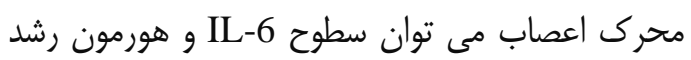
در بيماران مبتلا به IBS را در مقايسه با كروه كنترل

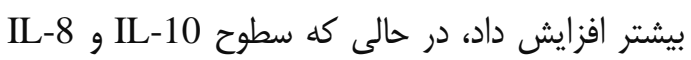

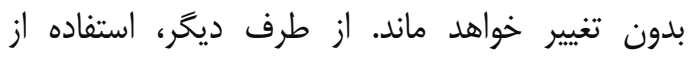
داروهاى ضدموسكارينى مانع از افزايش سطوح فاكتور

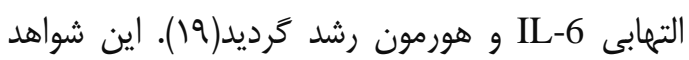
حاكى از تحت تاثير بودن سيسته ايمنى توسط سيسته

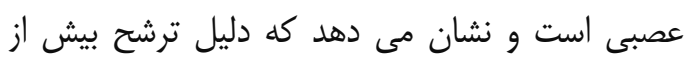

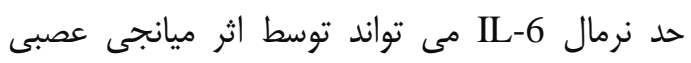

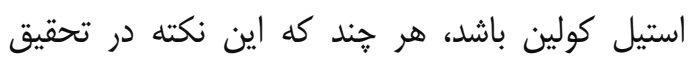
حاضر بررسى نشد. در حقيقت علائم بالينى ايجاد شده

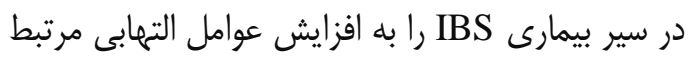
مى دانند. حتى نشان داده شده است كه ترشح سايتوكاين هاى ييش التهابى از سلول هاى ايمنى خون

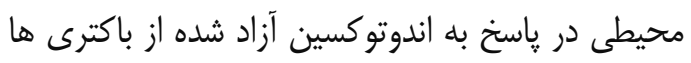

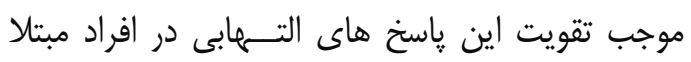

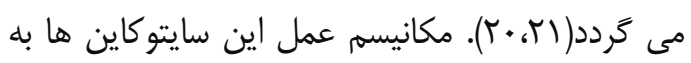

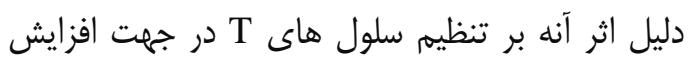

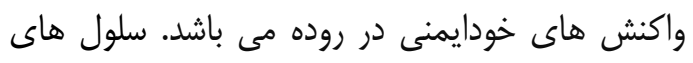

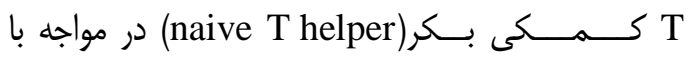
أنتى زن هاى بيكانه ارائه شده توسط سلول هاى

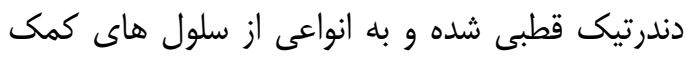

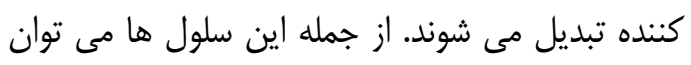

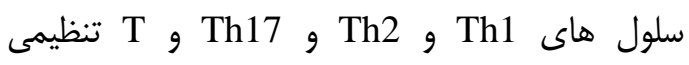

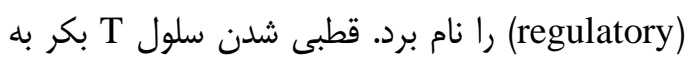

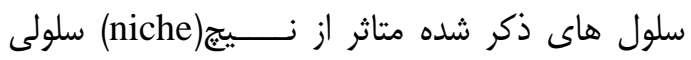

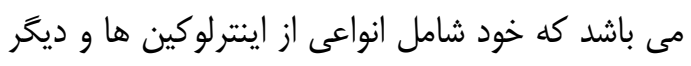

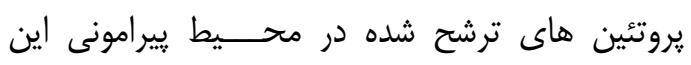

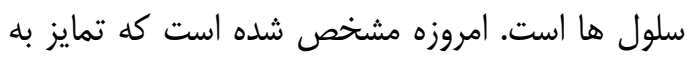

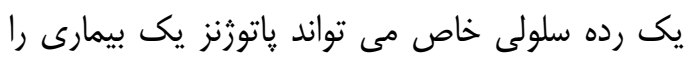

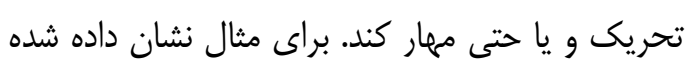

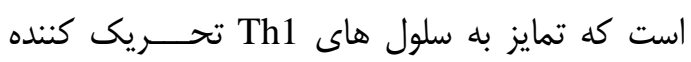

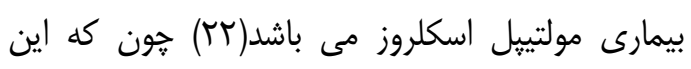

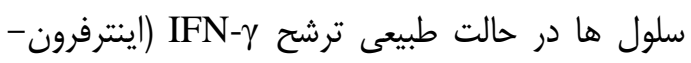

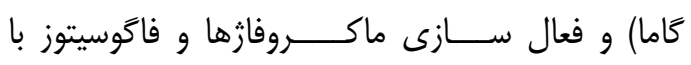
باكترى ها داخل سلولى و يروتوزواها مبارزه مى كنند 


$$
\text { كنترل ايتوكاين در بيماران مبتلا به IBS در مقايسه با كروه معاره }
$$

مطالعه اى كه توسط Seyedmehdi Seyedmirzaee

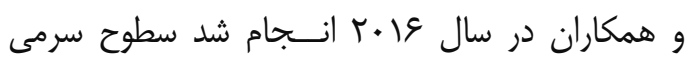

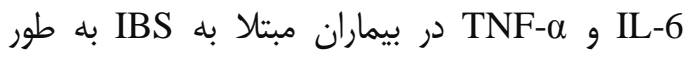

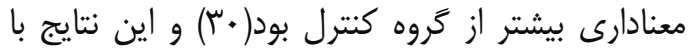

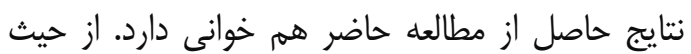

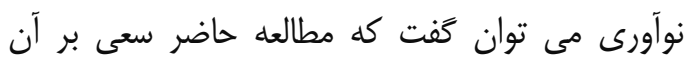

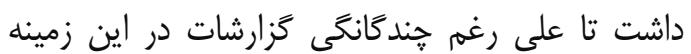
بتواند به بيشتر مشخص شدن سطوح اين دو سايتوكاين

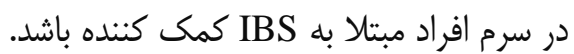
اين مطالعه نشان داد كه مقادير سرمى IL-6 و و سم TNF- $\alpha$

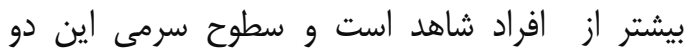

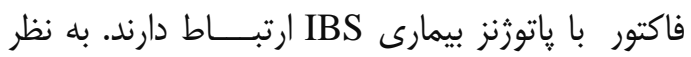

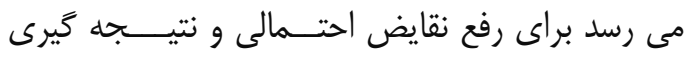

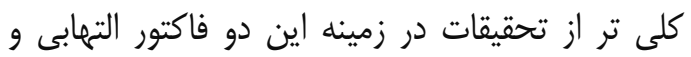

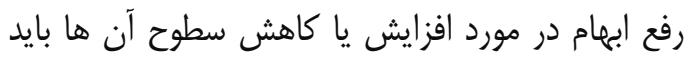

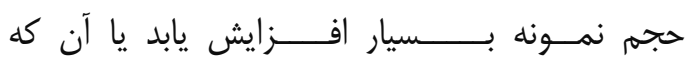

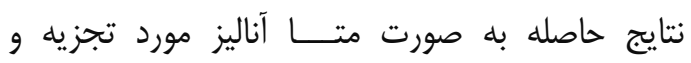
تحليل قرار گيرند. كد اخلاق: EC/92/H/132 تحليل قرار كيرن

\section{References}

1. Lembo AJ, Lacy BE, Zuckerman MJ, Schey R, Dove LS, Andrae DA, et al. Eluxadoline for irritable bowel syndrome with diarrhea. New England J Med2016; 374:242-53. doi: 10.1056/NEJMoa1505180 2. Thompson JR. Is irritable bowel syndrome an infectious disease? World $\mathbf{J}$ Gastroenterol2016;22:1331. doi: 10.3748/wjg.v22.i4.1331

3. Ju T, Naliboff BD, Shih W, Presson A, Liu C, Gupta A, et al. trauma severity and lack of confiding in others increases risk of having Irritable Bowel Syndrome. Gastroenterology2017;152: 711-2. doi:10.1016/S0016-5085(17)32482-4

4. Rostami A, Riahi SM, Haghighi A, Saber V, Armon B, Seyyedtabaei SJ. The role of Blastocystis sp. and Dientamoeba fragilis in irritable bowel syndrome: a systematic review and metaanalysis. Parasitol
دهنده تومورى توسط سلول هاى مونوسيت مزانتريك ترشح شده و تمايز سلول T بكر را به سلول هاى Th1

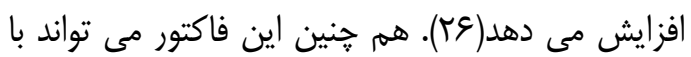

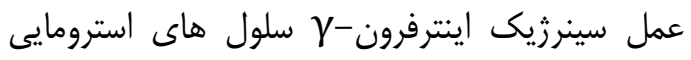

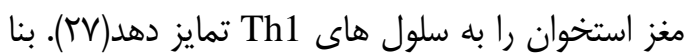
بر اين مى توان نتيجه كرفت كه نقش سيسته التهابى

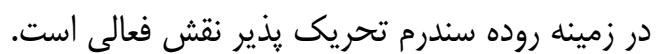

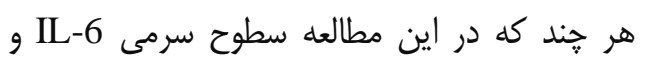

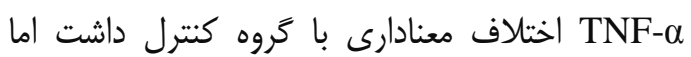
بررسى سير تحقيقات ييشين در زمينه سطوح سرمى

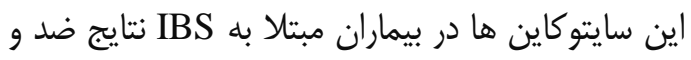

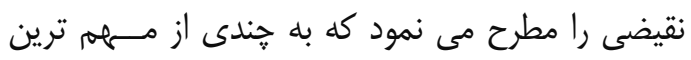

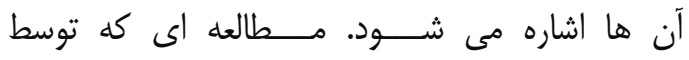

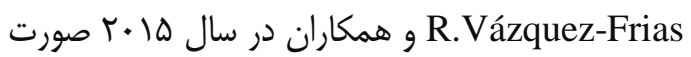
پذيرفت هر جند كه سطوح IL-6 را مورد بررسى قرار نداد اما در مورد فاكتور TNF-

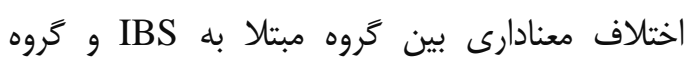

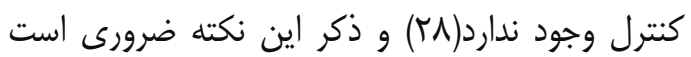
كه تعداد بيماران در اين مطالعه(ها نفر) كمتر از مطالعه

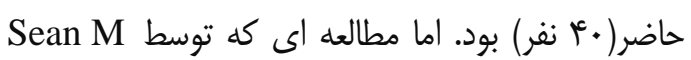

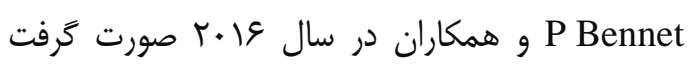
نشان داد كه افزايش در سطوح سرمى اين دو دان

Res2017;116:2361-71.

doi: 10.1007/s00436-017-5535-6

5. Defrees DN, Bailey J. Irritable Bowel Syndrome epidemiology pathophysiology diagnosis and treatment. Prim Care 2017;44:655-71.

doi: 10.1016/j.pop.2017.07.009

6. Boyer J, Saintpaul MC, Dadone B, Patouraux S, Vivinus MH, Ouvrier D, et al. Inflammatory cell distribution in colon mucosa as a new tool for diagnosis of irritable bowel syndrome a promising pilot study. Neurogastroenterol Motil 2017;2:238.doi: 10.1111/nmo. 13223

7. Patel SR, Singh A, Misra V, Misra SP, Dwivedi M, Trivedi P. Levels of interleukins 2, 6, 8 and 10 in patients with irritable bowel syndrome. Indian J Pathol Microbiol 2017;60:385. doi: 10.4103/IJPM.IJPM_544_16 
8. Alcamo A, Carroccio A, Liberto D, Presti EL, Fayer F, Dieli F, et al. Predominance of type 1 innate lymphoid cells in the rectal mucosa of patients with non-celiac wheat sensitivity: Reversal after a wheat-free diet. Clin Trans Gast2016;7:178. doi: e17810.1038/ctg.2016.35

9. Scully P, Mckernan DP, Keohane J, Groeger D, Shanahan F, Dinan TG, et al. Plasma cytokine profiles in females with irritable bowel syndrome and extra intestinal comorbidity. Am J Gastroenterol2010;105:2235-43. doi: 10.1038/ajg.2010.159

10. Goral V, Kucukoner M, Buyukbayram H. Mast cells count and serum cytokine levels in patients with irritable bowel syndrome.

Hepat

Gastroenterol2010;57:751-4.

11. Bashashati M, Rezaei N, Shafieyoun A, Mckernan DP, Chang L, Ohman L, et al. Cytokine imbalance in irritable bowel syndrome: a systematic review and metaanalysis. Neurogastroenterol Motil2014;26:1036-48. doi: 10.1111/nmo. 12358

12. Hasler WL. Traditional thoughts on the pathophysiology of irritable bowel syndrome. Gastroenterol Clin North Am 2011;40:21-43. doi: 10.1016/j.gtc.2010.12.004

13. Surdeablaga T, Baban A, Dumitrascu DL. Psychosocial determinants of irritable bowel syndrome. World $\mathrm{J}$ Gastroenterol 2012;18:616-26.

10.3748/wjg.v18.i7.616

14. Konturek PC, Brzozowski T, Konturek S. Stress and the gut pathophysiology clinical consequences, diagnostic approach and treatment options. J Physiol Pharmacol2011;62:591-9.

15. Ford AC, Talley NJ. Mucosal inflammation as a potential etiological factor in irritable bowel syndrome: a systematic review. J Gastroenterol2011;46:421-31. doi: 10.1007/s00535-011-0379-9

16. Schmulson M, Chey WD. Abnormal immune regulation and low grade inflammation in IBS does one size fit all? : Nature Publ Group 2012;3:123-7. doi: 10.1038/ajg.2011.427

17. Schmulson M, Pulido D, Rodriguez O, Morales N, Martinez R, Gutierrez MC, et al. Lower serum IL 10 Is an independent predictor of IBS among volunteers in Mexico. Am J Gastroenterol2012;107:74753. doi: 10.1038/ajg.2011.484

18. Schmulson M, Pulido D, Rodriguez Ó, Morales N, Martinez R, Gutierrez MC, et al. IL10 and TNF alpha polymorphisms in subjects with irritable bowel syndrome in Mexico. Rev Espanol Patol Dig 2013;105:392-9. doi: 10.4321/S113001082013000700004

19. Dinan TG, Clarke G, Quigley EM, Scott LV, Shanahan F, Cryan J, et al. Enhanced cholinergic mediated increase in the pro inflammatory cytokine IL6 in irritable bowel syndrome role of muscarinic receptors. Am J Gastroenterol2008;103:2570. doi: 10.1111/j.1572-0241.2008.01871.x

20. Liebregts T, Adam B, Bredack C, Roth $A$, Heinzel S, Lester $S$, et al. Immune activation in patients with irritable bowel syndrome. Gastroenterology2007;132:91320. doi: 10.1053/j.gastro.2007.01.046

21. Manchin H, Hsunchin C, Tsungchieh Y, Mingwei L, Jinglong $\mathrm{H}$. Investigation of Interleukin-10 promoter polymorphisms and interleukin-10 levels in children with irritable bowel syndrome. Gut Liver 2013; 7: 430-36. doi: 10.5009/gnl.2013.7.4.430

22. Fletcher J, Lalor S, Sweeney C, Tubridy $\mathrm{N}$, Mills $\mathrm{K}$. T cells in multiple sclerosis and experimental autoimmune encephalomyelitis. Clin Exp Immunol 2010;162:1-11. doi: 10.1111/j.13652249.2010.04143.x

23. Ohman L, Isaksson S, Lindmark AC, Posserud I, Stotzer PO, Strid H, et al. Tcell activation in patients with irritable bowel syndrome. Am J Gastroenterol 2009;104:1205-12. doi: 10.1038/ajg.2009.116

24. Polster A, Tessier A, Le Neve B, Törnblom H, Ohman L, Simren M, et al. Global cytokine profiles and association with clinical characteristics in patients with irritable bowel syndrome. Am J Gastroenterol 2016;111:1165. doi: 10.1038/ajg.2016.223

25. Kimura A, Kishimoto T. IL6 regulator of Treg/Th17 balance. European J Immunol 2010;40:1830-5. doi: 10.1002/eji.201040391

26. Jin $\mathrm{P}$, Zhao Y, Liu H, Chen J, Ren J, Jin $\mathrm{J}$, et al. Interferon $\gamma$ and tumor necrosis 
factor $\alpha$ polarize bone marrow stromal cells uniformly to a Th1 phenotype. Sci Rep 2016;6:26345. doi: 10.1038/srep26345

27. Munoz L, Albillos A, Nieto M, Reyes E, Lledo L, Monserrat J, et al. Mesenteric Th1 polarization and monocyte $\mathrm{TNF} \alpha$ production first steps to systemic inflammation in Rats with cirrhosis. Hepatology 2005;42:411-9. doi: 10.1002/hep.20799

28. Vazquezfrias R, Gutierrezreyes G, Urbanreyes M, Velazquez N, Fortoul TI, Lopez A, et al. Proinflammatory and antiinflammatory cytokine profile in pediatric patients with irritable bowel syndrome. Rev
Gastroenterol Mexico2015;80:6-12. doi: 10.1016/j.rgmx.2014.11.001

29. Bennet SM, Polster A, Tornblom H, Isaksson $\mathrm{S}$, Capronnier $\mathrm{S}$, Tessier $\mathrm{A}$, et al. Global cytokine profiles and association with clinical characteristics in patients with irritable bowel syndrome. Am J Gastroenterol2016;111:1165-76. doi: 10.1038/ajg.2016.223

30. Seyedmirzaee S, Hayatbakhsh MM, Ahmadi B, Baniasadi N, Bagherirafsanjani AM, Nikpoor AR, et al. Serum immune biomarkers in irritable bowel syndrome. Clin Res Hepatol Gastroenterol2016;40:631-7. doi: 10.1016/j.clinre.2015.12.013 


\title{
Elevated Serum Levels of IL-6 and TNF- $\alpha$ in Patients with Irritable Bowel Syndrome
}

\author{
Azizian $M^{l}$, Turki $H^{2}$, Mirzaei $A^{3 *}$
}

(Received: April 4, 2018

\begin{abstract}
Introduction: Irritable bowel syndrome (IBS) is accompanied by abdominal pain and intestinal discomforts. A line of evidence shows that the immune system plays important roles in the pathogenesis of the disease. Two main cytokines directing the immune system are IL-6 and TNF- $\alpha$ which may play a role in the immunopathogenesis of this disease. The present study aimed at investigating the serum levels of these cytokines in patients suffering from IBS.
\end{abstract}

Materials \& Methods: This comparative case-control study was conducted on 40 patients suffering from IBS (case group) and 40 people who were affected by the symptoms of gastrointestinal disorders but not suffering from IBS (control group). The serum levels of TNF- $\alpha$ and IL-6 cytokines were measured using enzymelinked immunosorbent assay. The amount of the above-mentioned cytokines was
Accepted: March 5, 2019)

compared using independent-t-test in both groups. Ethics code: $\mathrm{EC} / 92 / \mathrm{H} / 132$

Findings: The results showed significantly higher levels of IL- 6 and TNF- $\alpha$ in IBS patients, compared to those in the control group $(\mathrm{P}=0.0001)$. According to the results obtained from the Spearman rank correlation coefficient, there was a strong correlation between the serum levels of IL$6(\mathrm{P}=0.799, \mathrm{P}=0.000)$ and TNF- $\alpha(\mathrm{P}=0.788$, $\mathrm{P}=0.000)$ cytokines with IBS development.

Discussion \& Conclusions: This study shows that serum levels of TNF- $\alpha$ and IL-6 cytokines are significantly higher in the case group with IBS. Moreover, there is an association between serum levels of IL-6 and TNF- $\alpha$ with the pathogenesis of IBS.

Keywords: Enzyme-linked immunosorbent assay, Interleukin-6, Irritable bowel syndrome, Tumor necrosis factor- $\alpha$

1. Dept of Biology, Faculty of Basic Sciences, Arak Branch, Islamic Azad University, Arak, Iran

2. Infectious and Tropical Diseases Research Center, Health Research Center, Hormozgan University of Medical Sciences, Hormozgan, Iran

3. Dept of Medical Parasitology, Paramedical Faculty, Ilam University of Medical Sciences, Ilam, Iran

*Corresponding author Email: amirzaeii@yahoo.com 